\title{
Clinical Utility of Serum Neutrophil Gelatinase Associated Lipocalin (NGAL) as an Early Marker of Acute Kidney Injury in Asphyxiated Neonates
}

\author{
Channanayaka $C^{1}$, Venkatkrishnan $A^{2}$ \\ ${ }^{1}$ Dr. C. Chandrashekar, MBBS, MD. Associate \\ Professor, Department of Paediatrics, ${ }^{2} \mathrm{Dr}$. \\ Akila Venkatkrishnan, MBBS. MD Resident \\ Department of Paediatrics. Both from the \\ Jagadguru Sri Shivarathreeshwara Medical \\ College, Jagadguru Sri Shivarathreeshwara \\ University, Mysore, Karnataka, India.
}

\section{Address for correspondence:}

Dr. C. Chandrashekar, Associate Professor Department of Paediatrics,

Jagadguru Sri Shivarathreeshwara (JSS)

Medical College, Mysore, Karnataka, India

Tel: +919845054767

E-mail: chandruped23@gmail.com

Acknowledgements: We would like to thank the NICU team and the Department of Pediatrics, JSS Hospital, for their valuable support and guidance.

Funding: Nil

Conflict of Interest: None

Permission from IRB: Yes

Ethical dilemmas faced during study: No

\section{How to cite}

Channanayaka C, Venkatkrishnan A. Clinical Utility of Serum Neutrophil Gelatinase Associated Lipocalin (NGAL) as an Early Marker of Acute Kidney Injury in Asphyxiated Neonates. J Nepal Paediatr Soc 2016;36(2):121-125.

doi: http://dx.doi.org/10.3126/jnps.v36i2.14985

This work is licensed under a Creative Commons Attribution 3.0 License.

\begin{abstract}
Introduction: Acute Kidney Injury (AKI) is a common devastating problem in the NICU. Since the kidney is the second most affected organ in asphyxiated neonates (after the brain), a marker to determine kidney injury becomes important. Serum Neutrophil Gelatinase Associated Lipocalin (NGAL) determines acute kidney injury even before Blood Urea Nitrogen (BUN) or serum creatinine values rise. The aim of this study was to determine the clinical utility of NGAL as an early marker of acute kidney injury in asphyxiated neonates. Materials and Methods: This was a cohort study performed at a Level III NICU at JSS Hospital, Mysore, Karnataka, India over a period of two years. The study was conducted on30 term asphyxiated neonates and 30 term control neonates. Serum NGAL was measured within 6 hours after birth in an asphyxiated neonate using fluorescence immunoassay. Results: A highly significant increase in serum NGAL in cases group with a median of $323 \mathrm{ng} / \mathrm{ml}$ as compared to control group with median of $64 \mathrm{ng} / \mathrm{ml}$ was observed. Of the 30 asphyxiated neonates, 23 were positive for NGAL, and of these 3 had AKI.A cutoff value of $155 \mathrm{ng} / \mathrm{ml}$ for Serum NGAL could detect AKI in asphyxiated neonates with a sensitivity of $75 \%$ and a specificity of $23 \%$. Conclusion: NGAL is raised in Asphyxiated neonates both with and without kidney injury. Therefore, it is not a specific marker for acute kidney injury in asphyxiated neonates.
\end{abstract}

Key words: Neonatal asphyxia, Neonatal acute Kidney injury, Neutrophil Gelatinase Associated Lipocalin

\section{Introduction}

A cute kidney injury, previously known as acute renal failure, continues to represent a very common and potentially devastating problem in neonatal ICU. The kidney is the second major organ after the brain that is most commonly affected by perinatal hypoxia and the incidence of renal injury is as high as $57 \%$. Newborns who suffer from severe hypoxia often develop oliguria and acute renal failure from acute tubular necrosis (ATN). Acute kidney injury is most often diagnosed by measuring serum creatinine and blood urea nitrogen (BUN). Unfortunately, creatinine and BUN are unreliable indicators of 
$A \mathrm{KI}^{1}$. Serum creatinine, as a functional kidney marker, does not indicate kidney tissue injury; it only measures the accumulation of the endogenous marker as a consequence of decreased glomerular filtration rate (GFR).

Moreover, in newborns on their first days after delivery, serum creatinine reflects the maternal level for first 72 hours of birth. In addition, serum creatinine varies with age, sex, muscle bulk, and drugs. It will not rise until more than $50 \%$ of kidney function has already been lost. As for BUN, it is affected by hydration status. Hence identification of AKI biomarkers, both specific and nonspecific have been designated as a top priority by the American Society of Nephrology 2 . One of these specific markers is Neutrophil Gelatinase Associated Lipocalin or NGAL which is a $25 \mathrm{kDa}$ secretory glycoprotein, belongs to the lipocalin family of proteins. Human NGAL was originally isolated from the supernatant of activated neutrophils. Renal expression of NGAL increases dramatically after renal hypoxicischemia. This is reflected by the rapid rise of serum NGAL in a patient reported to have AKI. Serum NGAL has been demonstrated to be a sensitive and specific early marker of $\mathrm{AKI}^{3}$. The studies regarding utility of NGAL in prediction of $A K I$ in asphyxiated neonates are scare.

The aim of this study was to determine the clinical utility of NGAL as an early marker of acute kidney injury in asphyxiated neonates.

\section{Material and Methods}

This cohort study was conducted in Neonatal Intensive Care Unit of Pediatrics Department at JSS Hospital Mysore, Karnataka. A written informed consent was taken from the parents. Neonates included in the study were term who were appropriate for gestational age. Newborns with congenital malformations,chromosomal abnormalities, those suspected with inborn errors of metabolism, sepsis, mothers with pre-eclampsia,mothers with renal failure(AKI/CKD) or newborn born to mothers receiving nephrotoxic drugs were excluded. The 60 neonates considered for this study were divided as under:Study group-30 asphyxiated neonates fulfilling the inclusion criteria and having APGAR scoring of less than 7 at 5 minutes. The control group consisted of 30 apparently healthy neonates matched for age, sex and birth weight.

Complete history was elicited from the mothers including maternal, obstetric and perinatal history. Gestational age was calculated based on the date of last menstrual period and confirmed by neonatal examination using Modified Ballard Score ${ }^{4}$.Birth weight, sex and APGAR score at 1 and 5 minutes were recorded. Laboratory investigations included complete blood counts, C-reactive protein, urea, serum creatinine(done at birth and repeated at 48 hours of life), NGAL (done within first 6 hours of life). The study group was divided into HIE stages after 48 hours of life using the Saranath and Saranath classification ${ }^{5}$.

Acute Kidney Injury was defined as an absolute increase in serum creatinine of more than or equal to $0.3 \mathrm{mg} / \mathrm{dl}$ or an increase in serum creatinine by $50 \%$ or more ${ }^{6}$.

One $\mathrm{ml}$ of venous blood is drawn within six hours in asphyxiated newborns and serum NGAL is assessed by Alere Triage NGAL Test by principle of fluorescence immunoassay. ${ }^{7}$ A value of more than $155 \mathrm{ng} / \mathrm{ml}$ is taken as positive $\mathrm{NGAL}^{7}$.

Data was analysed using Microsoft excel 2016 and Epi info V 7. Quantitative variables were summerised as either mean and standard deviation or Median and inter quartile range depending on the distribution. Comparison was done using Student $t$ test for mean and Mann Whitney $U$ test for medians. The qualitative variables were summerised as proportions. Comparison was done using chi-square test. $P$ value of $<0.05$ was considered statistically significant.

Ethical clearance for conducting the study was obtained from the Ethical Committee of JSS University, Mysore.

\section{Results}

The clinical and laboratory characteristics among the studied neonates is listed in Table 1.In our study, among 30 asphyxiated neonates, $15(25 \%)$ were females and $15(25 \%)$ were males and among 30 controls, $18(30 \%)$ were females and $12(20 \%)$ were males. In the study group, 16 (53.3\%) children had HIE stage 1 and $14(46.7 \%)$ children were in HIE stage 2. Among HIE stage-1, nine (30\%) were females and seven $(23.3 \%)$ were males. Among HIE stage- 2, six (20\%) were females and eight $(26.7 \%)$ were males.

Of the 30 neonates, 23 neonates were positive for $\mathrm{NGAL}$, that is value greater than $155 \mathrm{ng} / \mathrm{ml}$ and seven were negative for NGAL that is value less than $155 \mathrm{ng} / \mathrm{ml}$. Out of 23 neonates positive for NGAL, three neonates had $\mathrm{AKI}$ and 20 neonates did not have AKI. Of the 23 neonates who had positive NGAL value, 10 neonates belonged to HIE stage-1 and 13 neonates belonged to 
HIE stage-2, while among the seven neonates who had NGAL value less than $155 \mathrm{ng} / \mathrm{ml}$, six neonates belonged to HIE stage-1 and one neonate belonged to HIE stage2 (Table 2).

A highly significant increase in serum NGAL in cases group with a median of $323 \mathrm{ng} / \mathrm{ml}(\mathrm{IQR}=159.75$ $798 \mathrm{ng} / \mathrm{ml}$ ) as compared to control group with median of $64 \mathrm{ng} / \mathrm{ml}(\mathrm{IQR}=54-74 \mathrm{ng} / \mathrm{ml})(p<0.001)$ is depicted in Fig.1.
Serum NGAL correlated with HIE severity. The median NGAL for HIE stage-1 was $165 \mathrm{ng} / \mathrm{ml}(\mathrm{IQR}=115$ $206.75 \mathrm{ng} / \mathrm{ml}$ )as compared to $827 \mathrm{ng} / \mathrm{ml} \quad(\mathrm{IQR}=469.5$ $860.5 \mathrm{ng} / \mathrm{ml})$ in HIE stage-2 $(p<0.001)$

Patients who were diagnosed as having AKI were found to have significantly higher level of serum NGAL with a median of $856 \mathrm{ng} / \mathrm{ml}(\mathrm{IQR}=653.5-917 \mathrm{ng} / \mathrm{ml})$ as compared with those without AKI who had a median of 305ng/ml (IQR=159.8-741.5ng/ml) with $p=0.246$ (Fig.2). NGAL value of $155 \mathrm{ng} / \mathrm{ml}$ had a sensitivity of $75 \%$ and negative predictive value of $85.7 \%$ for AKI (Table 3 ).

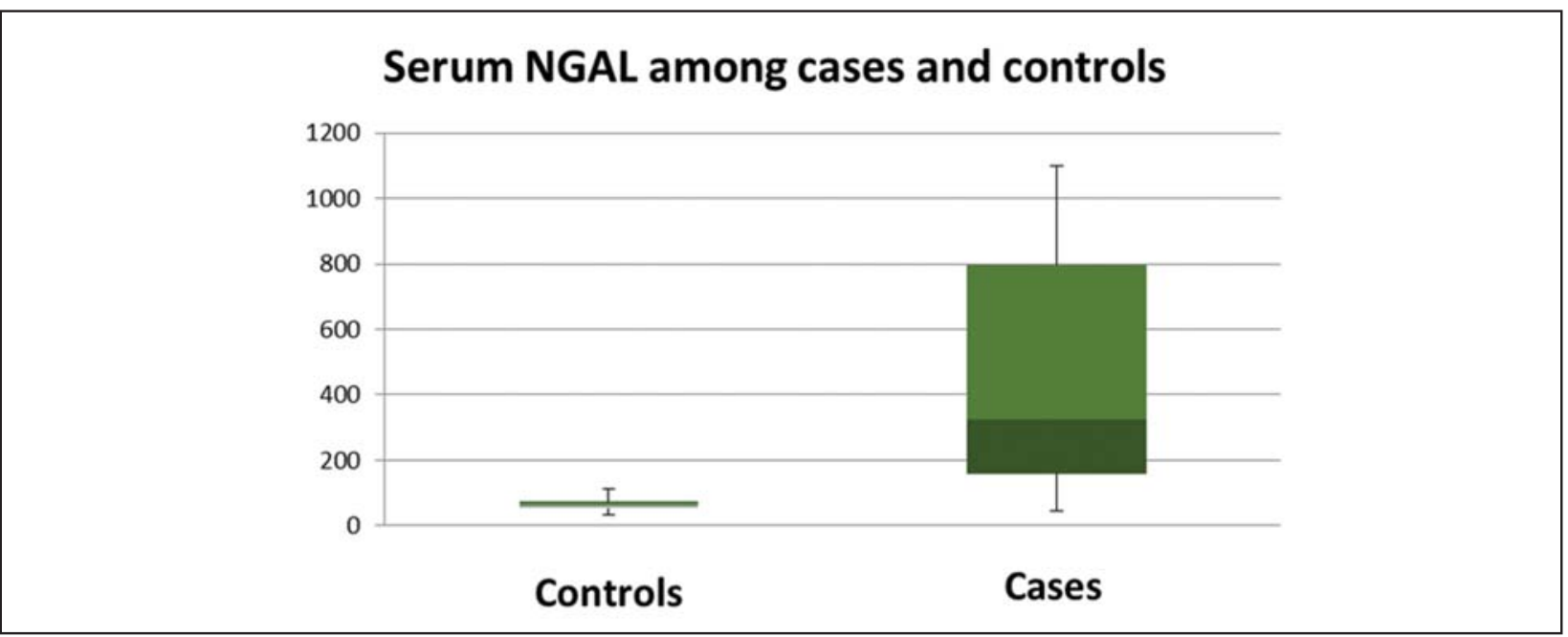

Fig 1: Comparison of serum NGAL levels between cases and controls

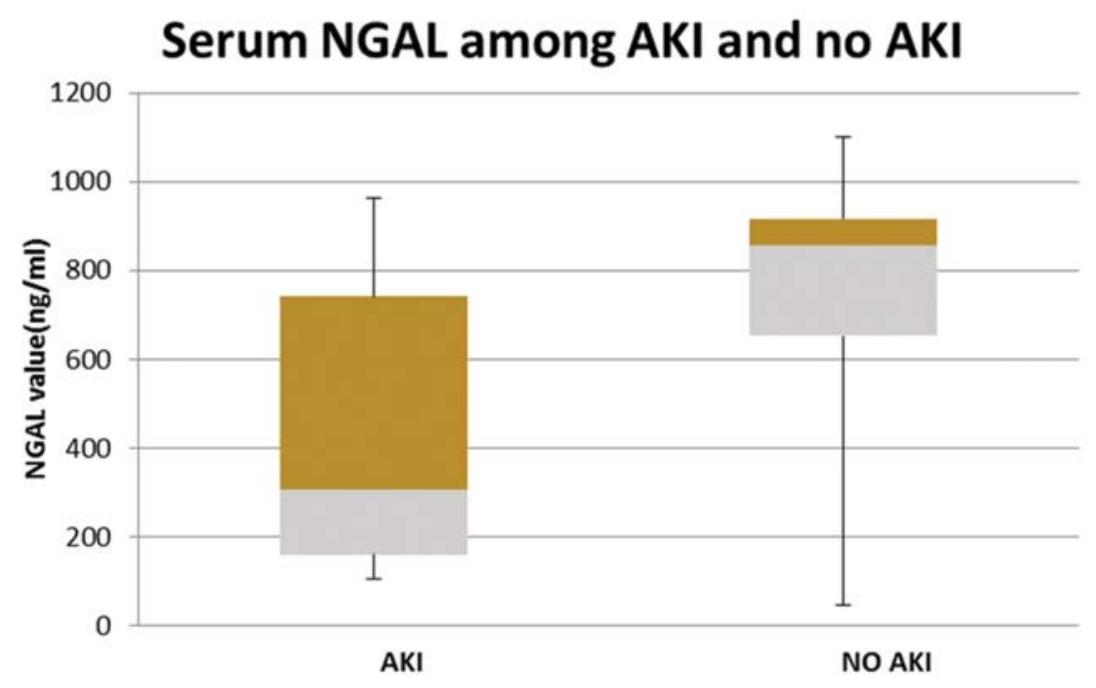

Fig 2: Comparison of serum NGAL values between neonates with and without kidney injury 
Table 1: Baseline characteristics of study groups

\begin{tabular}{lccc}
\hline & Asphyxia $(\mathbf{n}=\mathbf{3 0})$ & Normal $(\mathbf{n}=\mathbf{3 0})$ & $p$-value \\
\hline Gestational age (weeks) Mean (SD) & $38(0.86)$ & $37.2(6.5$ & $0.51^{*}$ \\
\hline Weight in grams Mean (SD) & $2899(384)$ & $2910(268)$ & $0.9^{*}$ \\
\hline Total leucocyte count Median (IQR) & $22665(17805-29210)$ & $8050(6830-10650)$ & $<0.05^{\#}$ \\
\hline Urea (mg/dl) Median ( IQR) & $36.5(20.5-46)$ & $22(20-26)$ & $0.004^{\#}$ \\
\hline APGAR 1 min Median (IQR) & $4(3-4)$ & $8(8-9)$ & $<0.05^{\#}$ \\
\hline APGAR 5 min Median (IQR) & $6(5-6)$ & $8(8-9)$ & $<0.05^{\#}$ \\
\hline Urine output ml/kg/hr Median (IQR) & $0.9(0.8-1.2)$ & No Data & NA \\
\hline Creatinine- 48 hrs mg/dl Median (IQR) & $1(0.8-1.28)$ & $0.8(0.8-1.0)$ & $0.076^{\#}$ \\
\hline${ }^{*}$ Student 't' Test, \# Mann Whitney U test & & & \\
\hline
\end{tabular}

Table 2: Relation of NGAL among HIE stages in asphyxiated neonates.

\begin{tabular}{cccc}
\hline & HIE-1 & HIE-2 & Total \\
\hline NGAL Negative & $6(20 \%)$ & $1(3.3 \%)$ & $7(23.3 \%)$ \\
\hline NGAL Positive & $10(33.3 \%)$ & $13(43.4 \%)$ & $23(76.7 \%)$ \\
\hline Total & $\mathbf{1 6 ( 5 3 . 3 \% )}$ & $\mathbf{1 4}(\mathbf{4 6 . 7 \% )}$ & $\mathbf{p = 0 . 0 2 4 ^ { * }}$ \\
\hline
\end{tabular}

${ }^{*}$ Chi square test

Table 3: Diagnostic ability of NGAL with respect to AKI in asphyxiated neonates

\begin{tabular}{cc}
\hline Sensitivity & $\mathbf{7 5 \%}$ \\
\hline Specificity & $23 \%$ \\
\hline Positive Predictive Value & $13 \%$ \\
\hline Negative predictive value & $85.7 \%$ \\
\hline Positive likelihood ratio & 0.97 \\
\hline Negative likelihood ratio & 1.08 \\
\hline
\end{tabular}

\section{Discussion}

NGAL expression increases greatly in the presence of inflammation and injured epithelia and therefore, NGAL is one of the earliest proteins induced in the kidney after ischemic or nephrotoxic insult. Consequently, NGAL significantly rises in blood and urine soon after $\mathrm{AKI}^{8}$.

In our study, serum NGAL measured in the first six hours of life showed significantly higher values in cases than control group. Serum levels of NGAL was higher in cases with acute kidney injury as well as without AKI. As we had very small number of neonates with kidney injury, we could not study them as separate group. This contrasts with another study where subjects with AKI had higher serum NGAL and urine NGAL (standardized to urine creatinine and absolute values) than controls at days 1,3 and $10^{9}$. Another study observed that both plasma and urine NGAL concentrations became significantly higher in both neonatal and non-neonatal patients with $\mathrm{AKI}^{10}$. However their cases had not suffered from asphyxial injury.

Renal failure in the neonate often occurs in the absence of oliguria ${ }^{11}$, and a high index of suspicion is required. We depended mainly on serum creatinine levels because none of the neonates in our study group had oliguria in the first day of life. Another study showed that serum NGAL levels at a cutoff value of $139 \mathrm{ng} /$ $\mathrm{mL}$ within the first 24 hours of admission to the PICU is highly sensitive for predicting $\mathrm{AKI}$ in critically ill children with septic shock with a sensitivity of $86 \%$ and a relatively poor specificity of $39 \%{ }^{12}$.

Raggal et.al demonstrated that serum NGAL level is elevated within six hours from birth in term neonates with perinatal asphyxia; in correlation with the evolving HIE severity. This finding is reflected in our study as well. High initial serum NGAL level was significantly associated with the subsequent diagnosis of $\mathrm{AKI}$ in these neonates. It was thus speculated by that author that early measurement of this biomarker in asphyxiated neonates can reliably predict the development of postasphyxial acute kidney injury ${ }^{13}$. As mentioned earlier, we had only four babies who developed AKI. We believe that analysis of this small number wouldn't reflect the true situation. 
Serum NGAL may not necessarily be an early marker of $\mathrm{AKI}$ in asphyxiated neonates, although most NGAL in urine or blood derives from the injured kidney, non- renal NGAL sources have been reported that might adversely affect the diagnostic criteria

\section{Conclusion}

NGAL is raised in Asphyxiated neonates both with and without kidney injury. Therefore, it is not a specific marker for acute kidney injury in asphyxiated neonates.

\section{References}

1. Bellomo R, Ronco C, Kellum JA, Mehta RI, Palevsky P.Acute renal failure - definition, outcome measures, animal models, fluid therapy and information technology needs, the second international consensus conference of the Acute Dialysis Quality Initative (ADQ) Group. Crit Care 2004;8:204-12.

2. American Society of Nephrology: Renal research report. J Am Soc Nephro/2005;16:1886-93.

3. L Axelsson, M Bergenfeldt, $\mathrm{K}$ Ohlsson.Studies of the release and turnover of a human neutrophil lipocalcin . Scandinavian J Clin Lab Invest 1995;55;7:577-88.

4. Saranath HB, Saranath MS. Neonatal encephalopathy following fetal distress:a clinical and electroencephalographics study. Arch Neurol 1976;33; 696-705

5. Ballard JL, Khoury JC, Wedig K, Wang L, Eilerswalsman BL, Lipp R. New Ballard score: expanded to include extremely premature infants. $J$ Pediatr 1991;119:417-23.

6. Mehta RL, Kellum JA, Shah SV, Molitoris BA, Ronco C, Warnock DG, Levin A; Acute Kidney Injury Network, Acute Kidney Injury Network: report of an initiative to improve outcomes in acute kidney injury. Crit Care 2007,11:R31.

7. Anja Haase-Fielitz, Michael Haase, and Prasad Devarajan, Neutrophil gelatinase-associated lipocalin as a biomarker of acute kidney injury: a critical evaluation of current status. Ann Clin Biochem 2014;51;(03):335-51.

8. Soni SS, Cruz D, Bobek I, Chionh CY, Nalesso F, Lentini $P$, et al. NGAL: A biomarker of acute kidney injury and other systemic conditions. Int Urol Nephrol 2010;42:141-50.

9. Sarafidis K, Tsepkentzi E, Agakidou E, Diamanti E, Taparkou A, Soubasi V, et al. Serum and urine acute kidney injury biomarkers in asphyxiated neonates. Pediatr Nephrol2012;27:1575-82.

10. Krawczeski CD, Woo JG, Wang $Y$, Michael R, Ma Q, Deverajan P. Neutrophil gelatinase-associated Lipocalin concentrations predict development of acute kidney injury in neonates and children after cardiopulmonary bypass. J Pediatr 2011;158;100915.

11. Gupta BD, Sharma P, Bagla JY, Parakh M, Soni J. Renal failure in asphyxiated neonates. Indian Pediatr 2005;42:928-34.

12. Mishra J, Dent C, Tarabishi R, Mitsnefes MM, Ma Q, Kelly C, et al. NGAL as a biomarker for acute renal injury after cardiac surgery. Lancet 2005;365:123138.

13. NM El Raggal, SM Khafagy,NH Mahmoud and SA El Beltagy, Serum Neutrophil Gelatinase-Associated Lipocalin as a Marker of Acute Kidney Injury in Asphyxiated Neonates.Indian Pediatr 2013;50:45962. 